\title{
Practices and Perceptions on Contraception Acceptance among Clients Availing Safe Abortion Services in Nepal
}

\author{
${ }^{1}$ School of Public Health, Curtin University, Australia \\ ${ }^{2}$ The University of New South Wales, New South \\ Wales, Australia \\ ${ }^{3}$ University of Southern Denmark, Denmark \\ ${ }^{4}$ BP Koirala Institute of Health Sciences, Nepal
}

Khanal V, ${ }^{1}$ Joshi $C^{2}{ }^{2}$ Neupane $D,{ }^{3}$ Karkee ${ }^{4}$
Corresponding author

Vishnu Khanal

School of Public Health, Curtin University

GPO Box U1987, Perth, Western Australia 6102

Email: khanal.vishnu@gmail.com,vishnu.khanal@ postgrad.curtin.edu.au

\section{Citation}

Khanal V, Joshi C, Neupane D, Karkee R.Practices and percepions on contraception acceptance among clients availing safe abortion services in Nepal. Kathmandu Univ Med J 2011;35(3):179-84.

\begin{abstract}
Background

The Government of Nepal has implemented safe abortion policy since 2002. There are 245 approved sites providing safe abortion services to women across the country. Family planning counselling is one of the components of the safe abortion policy, which is important to reduce unwanted pregnancy, maternal morbidity and mortality due to the consequences of unsafe abortion and the service burden.
\end{abstract}

\section{Objectives}

This study explains the perceptions, practices and factors affecting the use of family planning among abortion clients attending safe abortion services in Nepal.

\section{Methods}

A cross sectional study was carried out on September, 2008 enrolling 58 women who were waiting in the dressing room for safe abortion services in Paropkar Maternity Hospital, Nepal. All women attending hospital clinic for receiving safe abortion services were approached for interview till the targeted number was fulfilled. A convenience sampling was applied to reach the sample size.

\section{Results}

Of the 58 respondents, majority of the respondents were Hindus (83\%), residing in Kathmandu district (76\%); of the age group $20-29$ years (69\%); and $98 \%$ were married. One fifth $(20.68 \%)$ of the respondents had previous history of spontaneous or induced abortion. The main reason for abortion did not want any more babies/ complete family (45\%). The knowledge of modern contraception was high (98.27\%). The knowledge of emergency contraception was low (25.9\%). Side effects was the main reason $(48 \%, n=31)$ for discontinuation of contraceptives. Intention to use some modern family planning methods after the abortion was expressed by $83 \%$ clients. The major enabling factor for continued contraceptive use was the absence of side effects. The family planning counselling was acceptable for $91 \%$ clients.

\section{Conclusion}

Knowledge, acceptance of counselling service and intention to use family planning measure was high in the study participants. There is need to provide skills on adapting with the adverse effect of family planning measure through continuous education and reinforcement.

\section{KEY WORDS}

abortion, Contraception, family planning services, Nepal, unwanted pregnancy.

\section{INTRODUCTION}

The government of Nepal is committed to reducing unsafe abortion in line with the National Health Policy, $1991 .^{1}$ Before the endorsement of safe abortion policy, maternal mortality was very high, that is, 539 per 100,000 live births and unsafe abortion was one of the five main causes of maternal mortality. ${ }^{2,3}$ A study conducted in 1998 showed that $54 \%$ of all maternal deaths in hospitals were due to complications of unsafe abortion. ${ }^{2}$ Taking account of this massive burden of unsafe abortion, the Government of Nepal endorsed a safe abortion policy for Comprehensive
Abortion Care (CAC) on 2002. First legalized CAC service was started on March 2004. ${ }^{2}$ As of 2008/2009, there are 245 approved CAC sites providing services to about 81,000 women in a year. ${ }^{4}$

Nepal has a high unmet need for contraception (25\%), a low contraceptive prevalence rate $(44 \%)$ and a high level of mistimed and unwanted pregnancies (35.5\%). ${ }^{3}$ Although women who undergo abortion are at risk of subsequent unwanted pregnancies, in the majority of cases, repeat 
unwanted pregnancies may occur because family planning services are unavailable, inaccessible, ineffective, or culturally unacceptable to women. ${ }^{5}$

Several studies have been conducted in Nepal regarding knowledge of women on contraception, but research now needs to focus on how to increase their contraceptive acceptance, especially those seeking abortion. ${ }^{6}$ The objective of this study was to find perceptions, practices and factors affecting use of family planning among abortion clients attending Paropkar Shree Panch Indra Rajya Laxmi Devi Maternity Hospital, Nepal.

\section{METHODS}

\section{Procedure and participants}

This study was a descriptive cross-sectional study. After getting ethical approval for research proposal and tool from Institute of Medicine, Tribhuvan University, Nepal and ethical board of the research site, Paropkar Shree Panch Indra Rajya Laxmi Devi Maternity Hospital, Nepal, face to face oral interview was conducted with 58 participants. The study site was chosen based on location, and availability of regular service for medical abortion. Non probability convenience sampling method was used to enrol the study units. One week (between 7-12 September, 2008) was allocated for the data collection. All the participants (women) receiving medical abortion services were approached and only those participants who were willing to participate in the study were included in the study. Voluntary consent was taken before data collection.

\section{Research Instrument}

Interview questionnaire was used for this study. The questionnaire was derived from various studies. Socioeconomic and demographic questionnaire were adopted from a research tool developed by Johns Hopkin's University. ${ }^{7}$ Caste classification was adopted from Health Management Information System Nepal. ${ }^{1}$ Questionnaire for current use or non use, choices of family planning measures, satisfaction on counselling of family planning service and reason for opting for abortion were adapted from a facility based survey of Nepal on abortion services in 2006. ${ }^{2}$ Information source for family planning and reasons for discontinuation were adopted from research tools of Johns Hopkin's Universtiy. ${ }^{7}$ All the tools adapted from Johns Hopkin's research tool were made short. The draft questionnaire was pretested in the safe abortion service of Family Planning Association of Nepal (FPAN) in Kathmandu, Nepal. Interviewers (two) were enrolled for the study. Both of the interviewers were female and had completed community medical course. They were provided training and few sessions of mock data collection were held in a simulated condition. They were also involved in the pretesting of the questionnaire. Feedback was provided by the second author after each mock session and pre-testing of the questionnaire.

\section{Statistical analysis}

Collected data were checked for errors by the principle investigator. The data was then coded and entered for analysis using Statistical Package for Social Sciences (SPSS13). Descriptive statistics was analysed using frequency distribution and cross tabulation. For bi variate analysis, were categories education into literate and illiterate, and caste into relative advantaged (relatively advantaged Janjati and upper caste group) and disadvantaged (Dalit, disadvantaged Janjati, disadvantaged teria caste group).

Table 1. Descriptive Univariate Analysis.

\begin{tabular}{|c|c|c|}
\hline Variables & Categories & $\mathrm{N}=58(\%)$ \\
\hline \multirow[t]{3}{*}{ Age } & $<20$ & $3(5.2)$ \\
\hline & $20-29$ & $40(68.9)$ \\
\hline & $30-39$ & $15(25.2)$ \\
\hline \multirow[t]{3}{*}{ Religion } & Hindu & $48(82.8)$ \\
\hline & Buddhist & $7(12.1)$ \\
\hline & Others (Muslim, Christian, Kirat) & $3(5.1)$ \\
\hline \multirow[t]{5}{*}{ Education } & Illiterate & $9(15.5)$ \\
\hline & Primary & $10(17.2)$ \\
\hline & Secondary & $19(32.8)$ \\
\hline & Higher secondary & $11(19.0)$ \\
\hline & University degree or higher & $9(15.5)$ \\
\hline \multirow[t]{5}{*}{ Caste } & Dalit & $3(5.2)$ \\
\hline & Disadvantaged Janajatis & $14(24.1)$ \\
\hline & $\begin{array}{l}\text { Disadvantaged Non Dalit Terai } \\
\text { Caste Groups }\end{array}$ & $2(3.5)$ \\
\hline & Relatively Advantaged Janajatis & $7(12.1)$ \\
\hline & Upper Caste Groups & $32(55.2)$ \\
\hline \multirow[t]{5}{*}{ Occupation } & Agriculture & $4(6.9)$ \\
\hline & Service & $6(10.3)$ \\
\hline & Business & $7(12.2)$ \\
\hline & Housework & $36(62.2)$ \\
\hline & Student & $5(8.6)$ \\
\hline \multirow[t]{2}{*}{ Marital status } & Never Married & $1(1.7)$ \\
\hline & Married & $57(98.3)$ \\
\hline \multirow[t]{2}{*}{ Obstetric history } & Pregnancy for first time & 10 \\
\hline & Pregnancy for more than one times & 48 \\
\hline \multirow[t]{8}{*}{ Reason for abortion } & Unmarried & $1(1.7)$ \\
\hline & Affected Study & $9(15.5)$ \\
\hline & Complete Family & $26(44.8)$ \\
\hline & Economic Problem & $2(3.5)$ \\
\hline & Spacing & $14(24.1)$ \\
\hline & Endangered Health & $1(1.7)$ \\
\hline & Fetus Abnormality & $2(3.5)$ \\
\hline & FP Failure & $3(5.2)$ \\
\hline
\end{tabular}




\section{RESULTS}

\section{Socio-Demographic Characteristics of the Respondents}

Of the 58 respondents, majority of the respondents were Hindus (83\%), residing in Kathmandu district (76\%), of the age group 20-29 years (69\%), and belonging to nuclear family (45\%). Only a small number of respondents (3.5\%) belonged to the below poverty line, only about one sixth (16\%) were illiterate, more than half (62\%) were engaged in housework and almost all (98\%) were married.

\section{Obstetric and Gynaecological Information of the Respondents}

Seventeen per cent of the respondents $(n=58)$ were primigravida. Mean times of pregnancy excluding the current one were highest for the illiterates (2.8 times), the age group 30-39 years (3.1 times) .

About one fifth $(20.68 \%, n=58)$ of the respondents has previous history of spontaneous or induced abortion. The spontaneous/induced abortion was highest among the age group $20-29$ years $(66 \%, n=12)$ followed by the age group 30-39 (37\%, $n=12)$.

The respondents' mean number of living sons was 1.1 and the mean number of daughters was 0.73 . The main reason for abortion was complete family $(45 \%, n=26)$ followed by spacing $(24 \%, n=14)$ [table 1 ].

\section{Reason for Abortion in Relation To Background Variables}

The main reason for abortion among those less than 20 years of age $(67 \%, n=3)$ was "pregnancy affected their studies", while "completed family" was the main reason for 20-29 years group (40\%, $n=40)$, and for 30-39 years group $(67 \%, n=15)$. Overall ( $n=58)$, "completed family" was the main reason for abortion for $45 \%$ of the respondents, followed by birth spacing for $24 \%$.

\section{Family Planning (FP) Knowledge and Practice}

The knowledge of FP methods was near universal. This universal answer is from "Yes" and "No" answer of questionnaire. For method specific knowledge, the questionnaire was designed to capture multiple answers. The knowledge of modern contraception was $98.27 \%$ $(n=58)$ for all respondents. The knowledge of natural contraception was also higher $(93.1 \%, n=58)$. This decreased with increase in age and the literates had better knowledge about it. The knowledge of emergency contraception was rather low $(25.9 \%, n=58)$. The knowledge of emergency contraception also decreased with an increase in age (the lowest knowledge being 13\% ( $n=15)$ among the 30-39 years age group) and the literates had better knowledge of it $(28 \%, n=58)$. The major sources of information of FP methods were media $(67 \%, n=58)$ and family/friends $(65.5 \%, n=58)$.

A large portion of the clients $(76 \%, n=58)$ had used at least one of the FP methods during their life time. The illiterate women $(67 \%, n=9)$ were far behind in using any forms of contraception. This response was unprompted and was captured as multiple responses. Bi variate analysis using Fisher's exact test showed that there was no significant difference between the literate and illiterate women's knowledge regarding family modern family measures (modern and emergency contraceptives). Caste was not significantly associated with use of FP method.

Table 2: Bivariate analysis.

\begin{tabular}{|c|c|}
\hline & Fisher's exact test $P$ value \\
\hline \multicolumn{2}{|c|}{ Education as factor } \\
\hline Knowledge of Modern FP measures & .155 \\
\hline Knowledge of emergency contraceptive & .422 \\
\hline Ever used FP measure & .004 \\
\hline Intention to use FP after abortion & .646 \\
\hline \multicolumn{2}{|c|}{ Caste as factor } \\
\hline Ever used FP measure & .189 \\
\hline Intention to use FP after abortion & .065 \\
\hline
\end{tabular}

Of those respondents who had used FP methods during their life time, most of them across all classes had used modern contraceptives $(91 \%, n=44)$. A small portion $(16 \%, n=44)$ had used natural contraception (alone or in combination with modern contraceptives).

Of the total 14 (24\%) respondents who had never used any FP methods, negligence was found to be the main reason for non-use (33\%). Other reasons were couple separation $(16.7 \%)$, recent marriage $(16.7 \%)$, side effect $(8.3 \%)$, husband's opposition (8.3\%), medical illness (8.3\%) and unmarried (8.3\%).

For the discontinuation of FP methods, among 31 women using modern methods, side effects was the main reason (48\%, $n=31$ ) particularly among the respondents of 20-29 age group $(52 \%, n=40)$ and those engaged in housework (54\%, $n=34)$. Negligence was the second main reason for discontinuation $(36 \%, \mathrm{n}=31$ ) particularly among those less than 20 years $(100 \%, n=3)$ and those engaged in housework (42\%, n=34). Among 41 ever users of contraception, the rest 7 had used natural methods.

Intention to use some modern FP methods after the abortion was expressed by majority of the clients $(83 \%$, $n=58)$. The respondents belonging to age group of less than 20 years $(33 \%, n=3)$, the illiterates $(22 \%, n=9)$, and the disadvantaged Janajatis $(43 \%, n=14)$ were less willing to use any FP methods. Based on our bivaraiate analysis, literate women were more willing to use FP planning measures than illiterate women ( $p=.004)$ [ Table 2]. Caste was not associated significantly with intention to use FP method.

The reason behind willingness for future FP use was mainly due to freedom from tension of pregnancy $(40 \%, n=48)$. The second main reason was both economic reasons and the pain and stress endured during the abortion procedure 
(each 21\%, n=48).

The major enabling factor for continued contraceptive use was the absence of side effects across all classes of respondents $(62.5 \%, n=48)$. The efficacy of contraceptives was the second leading enabling factor $(20.8 \%, n=48)$.

The main reason for FP choice was counselling among all classes of clients $(48 \%, n=48)$, particularly for the illiterates $(71 \%, n=9)$, and the Muslims and Christians (both 100\%, $\mathrm{n}=2)$.

The FP counselling was acceptable for majority of the clients $(91 \%, \mathrm{n}=58)$.

\section{DISCUSSION}

\section{Perceptions regarding Contraception}

The knowledge, attitude and past experiences of women concerning contraception are the major factors for the acceptance and correct continued use of any FP methods.

In this study, the contraception knowledge was quite high among all classes of respondents (98.3\%) which is similar to the findings of Nepal Demographic and Health Survey 2006. This may be due to the fact that majority of the respondents were literate (84\%) and many resided in urban areas (59\%). A significant finding was that the knowledge of modern contraception was 100\% among these respondents. A higher proportion of respondents reported knowing a modern method than a traditional method, which is also similar to the findings of Nepal Demographic and Health Survey 2006. ${ }^{3}$ This rules out the explanation that the findings may be due to the result of yes or no response.

Though the knowledge of FP methods was quite good, this was not translated into action which is supported by the findings that $21 \%$ of the respondents had never used any FP methods while $71 \%$ of those who used FP method discontinued it. Study in Brazil in similar settings of post abortion care has also reported high level of knowledge regarding contraceptive services but low level of consistent use of the contraceptive measures. ${ }^{8}$ Moreover, having onefifth of the women not using contraception, vast majority of them from the most accessible place of the country, reflects that there is more need to give complete education and adequate skills to start the use and continuation of available contraceptive services.

A major portion of respondents took abortion as a means of contraception. This is supported by the fact that complete family (45\%) and birth spacing (24\%) were the main reasons for the index abortion. This findings should be taken as a very alarming situation that Ministry of Health and Population, Nepal has not envisioned and ratified safe abortion service as a mean of family planning, rather is a means to save mothers, victims of coercion and to ensuring the right to choose the right time for being pregnant for the women. This service is not envisioned as an alternative to the family planning services provided by the government. ${ }^{1}$ This contributes to burden in terms of cost, stretches the already scarce resources in health care sector of Nepal and moreover, is less sustainable to continue in this scenario.

A significant portion of the clients (17\%) were primigravida and though they were counselled about the chances of infertility following an abortion, women were still keen to abort the foetus.

\section{Practices of contraception pre-abortion}

Seventy six per cent respondents had used FP method in their life time, of which $91 \%$ had used modern contraception. Our findings about association with education with use of FP methods is plausible with the existing belief that the more educated women, the better FP used will be. It also showed that mere knowing name of FP methods is not enough to enable women to use FP. Seventy one per cent discontinued it. Method failure was a minor reason for the index pregnancy associated mainly with natural method use and condom use (46\% used condom alone or in combination with other FP methods). The main reason for FP discontinuation was due to side effects. Moreover, for those who were using natural methods, failure was the major reason, reflecting need to improve skill on using natural methods The high level of knowledge and low level of use can be understood in different ways. First, having knowledge might have been reported as "having heard about FP methods". There are many social marketing and media campaigns going on in Nepal, as a result of which many women might have heard about methods of FP. ${ }^{9}$ But, adopting into behaviour as use of contraception needs time, full knowledge and skills. Hence, just hearing about availability of the methods may not be adequate to translate into the behaviour. ${ }^{8}$ This fact was reflected in this study as one -fourth of the respondents had never used any FP.

\section{Future Intention of Contraception use}

A major portion of clients (83\%) expressed their intention to use some FP methods after the abortion, of which $98 \%$ chose modern contraception. This finding is similar to previous finding from a facility based survey of 2006 where 84-95\% of women accepted post abortion contraceptives. ${ }^{2}$ Counselling was the main reason for FP choice among $48 \%$ of them. Post abortion family planning counselling is a better and sensitive time to provide better realization to the women and partner that family planning measures can save their time, pain and resources. ${ }^{10}$ Provision of post abortion counselling and contraception is also needed to meet the service standard. ${ }^{10}$ One important factor should be noted that in most of previous studies, it is reported that contraception acceptance was perceived as a prerequisite to getting CAC services. This fact not only violates the principle of voluntary counselling and client centered care but also increases chances of discontinuation in the future. ${ }^{2,6}$ If the post abortion counselling is not sustained by repetitive counselling during consecutive visits, there 
are more chances of repeated abortion. ${ }^{11}$ Moreover, family planning is only continuous when there is continuous reinforcement on building skills on sustaining behaviour change. ${ }^{6}$

\section{Enabling and impeding factors for women's contraceptive use}

The absence of side effects was the major enabling factor for continued contraceptive use (62.5\%) across all classes of respondents. "Side effects" was the main impeding factor for FP continuation, accounting for $48 \%$ of the total FP method discontinuation. Though contraceptives use are promoted as an integral part of the CAC services, evidences are there that oral contraception can produce disturbances in hypothalamic-pituitary-ovarian system (disturbance in release of follicle stimulating hormones), causing bleeding patterns to be less predictable and/or increased thrombotic risk. ${ }^{12}$ Similarly, injectables and IDUs also have their own side effects. But, in the service user's perspective, bleeding pattern, weight gain, headache and abdominal pain or discomfort are the major perceived side effects of the contraceptives. ${ }^{13}$ Though side effects are reported to be the major cause, other non side effects factors such as husband's support, social level of acceptance and perceived benefits of the contraception were found to be the major reinforcing factors related to discontinuation of the contraception use. ${ }^{13}$ This pattern has been partially reflected in this study having negligence as the second important reason for discontinuation (36\%). Moreover, in the study setting only pre-abortion counselling was provided, post abortion counselling was completely absent. Even this pre-abortion counselling lacked informed choice and voluntary acceptance of FP methods. All these factors have potential for discontinuation of the contraception and increased frequency of unwanted pregnancy as well. ${ }^{14}$

The FP counselling could provide detailed information on all the available contraceptive methods, their benefits and side effects, rather than the counsellor herself choosing a method for the client. This might enable a woman to switch to another method if she experiences side effects with the present method. The counselling could also focus on the joint reproductive FP responsibility of men and women, not blaming the pregnancy alone on women and involving men in the counselling.

The case study on repeat abortion depicts the nonuniformity of SAS services in the public and private health facilities. A system of quality assurance should be there to ensure counselling as a prerequisite to abortion, should be provided to all the clients, whether in a public or private SASs centre.

Though the study has some significant findings, there are two major limitations associated with this study. The first, the sample is small and not randomly selected, hence it will not be generalisable to all populations who are undergoing for abortion services. The second limitation is that the women who participated in the study were primarily from the capital city of Nepal. These findings hence may not reflect the actual situation of the women in other areas of Nepal.

\section{CONCLUSION}

The acceptance and intention to use contraceptives after abortion service was higher among the study participants. Injectable contraceptive was the most preferred one. Increasing choices of family planning to embark the philosophy of client centered choices, referring back for follow up counselling to health facilities which is near to clients residents, focussing on skills to adapt with the side effects of contraceptives and providing complete knowledge on natural and modern methods of contraception to reduce failure are areas for improvement which were identified in research. This study also reinforces the fact that women are more receptive to adapt a behaviour change, more willing to avoid future unwanted pregnancy at post abortion period, hence family planning counselling should be tailored for better adaptation of the behaviour.

\section{ACKNOWLEDGEMENTS}

We acknowledge Professor Madhu Dixit Devkota and Department of Community Medicine and Family Health, Institute of Medicine, Nepal for their support during this study.

\section{REFERENCES}

1. Ministry of Health and Population. Annual Report. Kathmandu, Department of Health Services;2009/2010 2008/2009.

2. CREPHA. Nepal Comprehensive Abortion Care National Facility Based Abortion Survey 2006. Kathmandu [Nepal]: Government of Nepal, Centre for Research on Environment Health and Population Activities,2006.

3. Ministry of Health and Population [Nepal], New ERA [Nepal], Macro International Inc. Nepal Demographic and Health Survey 2006: Key Findings. Kathmandu, Nepal, and Calverton, Maryland, USA: Ministry of Health and Population, New ERA and Macro International Inc.2007.

4. Ministry of Health and Population. Annual Report. Kathmandu, Department of Health Services;2008/2009 2008/2009.

5. Lamichhane P, Harken T, Puri M, Darney PD, Blum M, Harper CC, et al. Sex-selective abortion in Nepal: a qualitative study of health workers' perspectives. Women Health Iss 2011 May-Jun;21(3 Suppl):S37-41.

6. Karki Y, Basnett I, Clark K, Ganatra B, Stucke S. An Extraploratory Study of Complications From Comprehensive Abortion Care (CAC) Improvement of Quality of Care in Nepal. Kathmandu [Nepal]2009.

7. Johns Hopkins Bloomberg School of Public Health Center for Communication Programs. Baseline Survey for the MNH Program in Three Districts of Nepal - Pregnant Woman Questionairre2002.

8. Ferreira AL, Souza Al, Lima RA, Braga C. Choices on contraceptive methods in post-abortion family planning clinic in the northeast Brazil. Reprod Health 2010;7:5.

9. Stash S. Explanations of unmet need for contraception in Chitwan, Nepal. Stud Fam Plann 1999 Dec;30(4):267-87. 
10. Mittal S. Contraception after medical abortion. Contraception 2006 Jul;74(1):56-60.

11. Upadhyaya UD, Brown BA, Sokoloff A, Raineb TR. Contraceptive discontinuation and repeat unintended pregnancy within 1 year after an abortion. 2011 Elsevier Inc. 2011.

12. Gaffield ME, Kapp N, Ravi A. Use of combined oral contraceptives post abortion. Contraception 2009 Oct;80(4):355-62.
13. Westhoff CL, Heartwell S, Edwards S, Zieman M, Stuart G, Cwiak C, et al. Oral contraceptive discontinuation: do side effects matter? Am J Obstet Gynecol 2007 Apr;196(4):412 e1-6; discussion e6-7.

14. Rahman M, DaVanzo J, Razzaque A. Do better family planning services reduce abortion in Bangladesh? Lancet 2001 Sep 29;358(9287):10516. 